\title{
The effects of teaching methods of palliative care on life pattern of old women with chronic pain
}

\author{
Elham Hesari (1), Zahra Sabzi (2), Shohreh Kolagari (2) \\ (1) MSc in Geriatric Nursing, Golestan University of Medical Sciences, Gorgan, Iran; (2) \\ Nursing Research Center, Golestan University of Medical Sciences, Gorgan, Iran \\ This article is distributed under the terms of the Creative Commons Attribution Noncommercial License (CC BY-NC 4.0) which permits \\ any noncommercial use, distribution, and reproduction in any medium, provided the original author(s) and source are credited.
}

\begin{abstract}
Chronic pain is among problems of old people and causes changes in their life pattern and processes. Teaching palliative care can help old people suffering from chronic pain to live an active life. The aim of this research was to determine effects of educating of palliative care on life pattern of elderly women with chronic pain. The present study was a Quasi-experimental design with pre-test and post test was conducted on 30 elderly women suffering from chronic pain in 2018 in Iran. The Questionnaire for evaluating the Pattern of Life with Pain in the elderly was filled before the intervention, group educating of palliative care was carried out using an educational package, and the questionnaire was completed again immediately and one and three months after. The data was analyzed using mean, standard deviations, Fisher's F test, and Greenhouse-Geisser and Bonferroni post-hoc test by employing SPSS-16. Mean changes before teaching palliative care significantly differed from those of immediately and one and three months after the educational program $(p=0.0),(p=0.004)$. There were significant differences between the stages of immediately and one month after the educational program and that of three months after it $(\mathrm{p}=0.001),(\mathrm{p}=0.002)$. Concerning the personal life patterns, there were statistically significant differences between the stage immediately after the educational program and those before the intervention and three months after it $(p=0.005),(p=0.000)$. Regarding the social life pattern, only the stage of one month after the educational program significantly differed from that of three months $(p=0.005)$. Mean growth in life pattern of the old women suffering from chronic pain in the stages after the intervention indicated the importance of and the necessity for palliative care during old age. Moreover, the success of this education three months after the educational program as compared to immediately and one month after it indicates that allocation of sufficient time plays a very important role in transferring information and in teaching methods of palliative care to old people.
\end{abstract}

Key Words: elderly, life pattern, chronic pain, palliative care.

Eur J Transl Myol 29 (4): 313-319, 2019

Elderly with its accompanying diseases is a major growing problem of global health. ${ }^{1}$ According to the United Nations predictions, the world-wide population of old people will increase from 10 percent in 2007 to about 22 percent in $2050 .^{2}$ In Iran, old people population will reach 10 million by the end of $2019 .^{3}$ Old age is a physiological, progressive and irreversible process, ${ }^{4}$ accompanied by reduced performance, independence, but increased illness levels, which requires high level of care. ${ }^{1}$ Old people and healthcare teams, indeed, face the great challenge of problems, disabilities and chronic illnesses associated with increasing age. ${ }^{5}$

Chronic pain is one of the most prevalent and important problems of old age. Pain is a common experience for old people and one-third of them suffer from chronic pain, and old menopausal women experience it more intensely. ${ }^{6,7}$ Pain is chronic when recurrent and lasting more than three months. Prevalence rate of chronic pain among old people varies from 25 to 50 percent, and its estimated rate for old people residing at nursing homes reaches 83 percent. ${ }^{89}$ Chronic pain can gradually cause or intensify disability in carrying out daily activities and reduce quality of life. ${ }^{10}$ Chronic pain of non-malignant origin, such as that related to osteoarthritis, osteoporosis, and vascular disorders, is common. It has visceral or somatic nature, and, if progressing, cause changes in the nervous or hormonal system. With increasing age, it eventually influences the life pattern of patients. ${ }^{11-13}$ 
Living with chronic pain determines dependence on others, reduced physical, mental social abilities, and great need for medications that will gradually be followed by social isolation, loneliness, despair, hopelessness, and severe depression. ${ }^{3,13}$ If not well managed, this life pattern can make people physically inactive and housebound, ${ }^{10,14}$ so that old people need greater care. ${ }^{15}$ One is palliative care. ${ }^{13}$ Indeed, more than two-thirds of people suffering with chronic pain require some kind of palliative care. ${ }^{16}$ Palliative care is an approach that concentrates on the patients themselves to upgrade their physical, mental, social, and spiritual aspects of life so that they may confront life limiting diseases. ${ }^{17}$ In other words, it is the science and art of upgrading the quality of life through improving the conditions of living with chronic diseases that bring greater comfort and tranquility to patients. ${ }^{18}$ Therefore, it seems that teaching palliative care may improve living conditions regardless of the type of chronic illnesses. ${ }^{19,20}$ Sadat Bahador et al. (2013), Campbell et al. (2012) and Evangelista et al. (2012) showed that quality and pattern of life of patients improved through offering palliative care and continuous follow up ${ }^{21-23}$ Given the nature and long duration of chronic illnesses, in nursing homes a palliative care system that emphasizes physical, mental, emotional, spiritual, and social aspects of life is mandatory. It may offer great help in active living of old people despite the existing problems. ${ }^{24,25}$ The aim of the present study was to determine effects of educating palliative care on life patterns of elderly women with chronic pain.

\section{Materials and Methods}

This is a Quasi-experimental design study with pre-test and post test was conducted on old women with chronic pain in the North of Iran, Gorgan in 2018.

\section{Inclusion criteria}

i) Being 60-65 years old, suffering from non-malignant musculoskeletal, rheumatic, neuro-skeletal, neurovascular pain confirmed by a physician at the elderly Center; ii) Absence of cognitive impairment, such as forgetfulness, dementia, and delirium as reported by the old women or announced by the officials at the elderly Center; iii) Non-participation in educational sessions with similar subjects at present or in the past; iv) Not being deaf or blind based on the diagnosis of a doctor.

\section{Exclusion criteria}

i) Changes in conditions and/or treatment based on the diagnosis of a physician or on the old women reports; ii) Malignant diseases.

\section{Data Collection}

Following Kathy Jo Gutgsell, ${ }^{26}$ the sample size of 30 was determined using the equation:

$$
\mu_{\mathrm{T}}-\mu_{\mathrm{F}}=1.97 ; \mathrm{SD}_{\text {pre }}=1.72 ; \mathrm{SD}_{\text {pos }}=2.59 \alpha=0.05 \beta=0.1
$$

The old women qualified to enter the study were selected by convenient sampling and, after obtaining informed consent, the enrolled persons were divided into 6 groups with 4 members and one group with 6 members. At the research beginning, i.e., before the educational program (EP), a demographic questionnaire and a Questionnaire for evaluating the Pattern of Life with Pain in the Elderly were filled in interviews with the old women (Before). Group education on methods of palliative care using the educational package was then carried out at the elderly Center in two weekly sessions for 4 weeks. According to the timetable and the grouping, the old women were invited to the educational sessions in the morning and afternoon.

The educational package was prepared by using new books and articles on palliative care, through receiving help from specialists, and taking into consideration the guidelines published by the Ministry of Health, Treatment and Medical Education. Content validity was confirmed by a panel of experts that included specialists in medical groups and geriatric nursing and face validity by target groups. The educational package included: i) Management of pain and physical problems by pharmacological and non-pharmacological actions. The former included regular use of analgesic and antiinflammatory drugs prescribed by a physician, not taking nonprescription drugs, not doubling drug doses, and being watchful regarding drug complications. The latter included physical activities to alleviate pain, sport and corrective exercises, fall and injury prevention, and adopting proper posture when carrying out daily activities; ii) Nursing care with an emphasis on sleep pattern and compliance with the diet, abstaining from smoking; iii) Mental, spiritual, and religious care such as taking part in prayer rituals and worship rites; iv) Social communication such as self-love, increasing selfconfidence, participation in gatherings with friends and acquaintances, and adjusting life patterns. The face-toface educating technique was employed for the old women. The questionnaires were completed immediately after the EP ended and one and three months later by reinviting the persons at the Elderly Day Center (After). During this 1-3 months period, and also between the two weekly sessions, follow up was carried out in person or by telephone to help the old women (if needed) and to answer their questions on matters related to the research goals. A demographic questionnaire that included 9 questions (age, education level, economic status, marital status, housing status, lifestyle, insurance type, type of health insurance policy, location of the pain, and underlying diseases). The standard Questionnaire for evaluating the Pattern of Life with Pain in the elderly was the one that Shirazi et al. (2015) designed, measured and validated for psychometry, content, face, and construct. ${ }^{27}$ The reliability of the entire questionnaire, determined by using the internal consistency method, was $0.89 .{ }^{27}$ This questionnaire includes 15 items: eight on personal life pattern (items 1-8) and seven on social life patterns (items 9-15). The items were rated on a 5-point Likert scale with reverse scoring. The scores were given 


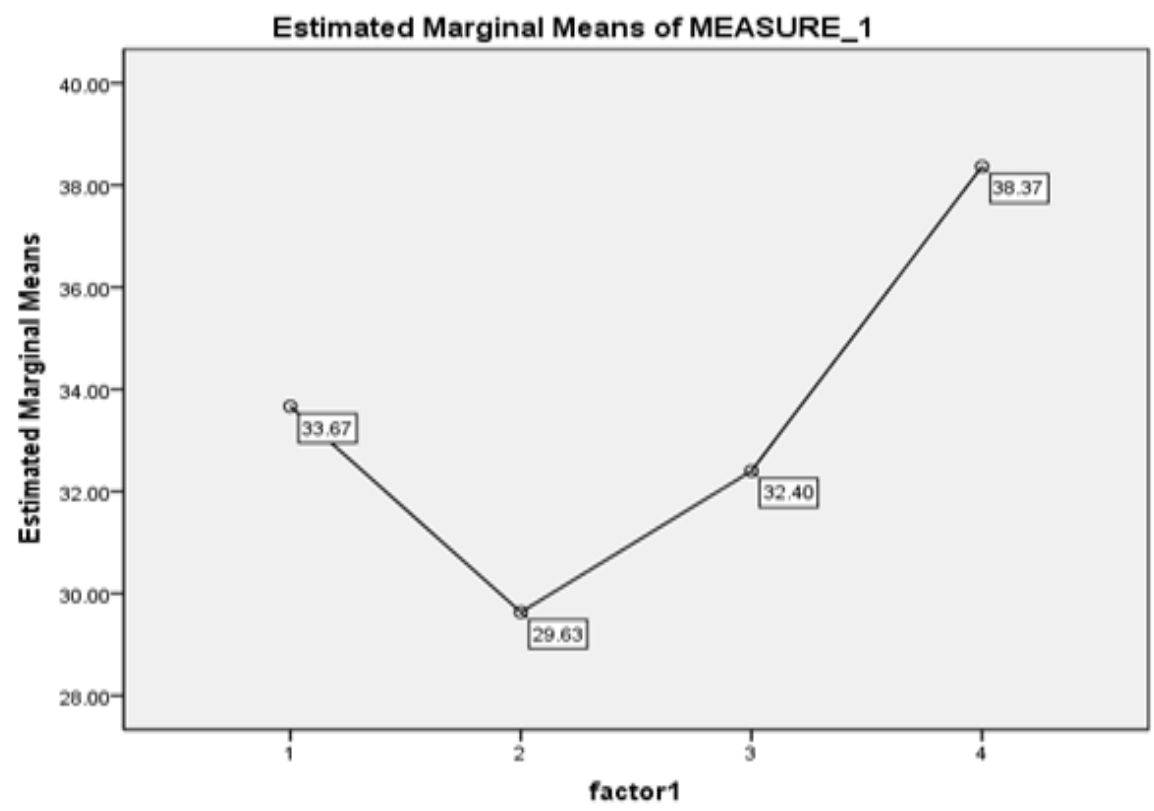

Fig 1. Scores for life pattern before EP (1), soon after its end (2) and at one (3) and three (4) months delay.

considering the negative connotation ( 0 : always, 1 : often, 2: sometimes, 3: rarely, and 4: never). The total score ranged from zero to 60 , and the higher scores indicated more suitable life pattern. The collected data were entered into SPSS-16, and the values for the before and after stages of the studied traits were described by calculating the means and standard deviations. Fisher's test was used in cases with normal distribution of the samples and the Greenhouse-Geisser test in cases without normal distribution of the samples to compare the mean scores for life patterns at the four different periods in order to determine the effect of intervention and study the impact of the educational program on life pattern of the old women with chronic pain. Bonferroni post-hoc test was employed to compare the three stages and assess the differences between the means of the scores for life pattern in the stages before the EP, immediately after it, and one and three months later. The significance level for all tests was 0.05 .

\section{Results}

The thirty old women were divided into the pre- and postintervention groups. Demographic and clinical information revealed that most of them were 60-70 years old (80\%), married (73.3\%), and suffered from underlying diseases (70\%). In addition, $53.3 \%$ had low educational levels, $47.7 \%$ lived with family members, $46.7 \%$ enjoyed average economic status, and $36.5 \%$ reported pain in the upper and lower extremities.

The mean score for life pattern before the EP was $33.67 \pm 1.39$, which decreased to $29.63 \pm 1.62$ immediately after the EP, but rose to $32.40 \pm 1.44$ and to $38.36 \pm 1.01$ one and three months after the EP, respectively. Therefore, the score for life pattern exhibited a declining

Table 1. Pairwise comparisons of the mean differences between the scores for life pattern of the old women with chronic pain before EP, immediately, one month, and three months after

\begin{tabular}{|c|c|c|c|c|c|}
\hline $\begin{array}{l}\text { Changes in } \\
\text { mean scores } \\
\text { for } \\
\text { life patterns }\end{array}$ & Mean \pm SD & Before EP & $\begin{array}{c}\text { Immediately after } \\
\text { EP }\end{array}$ & $\begin{array}{c}1 \text { month after } \\
\text { EP }\end{array}$ & $\begin{array}{c}3 \text { months after } \\
\text { EP }\end{array}$ \\
\hline Before EP & $33.67 \pm 1.39$ & & $\begin{array}{c}-4.03 \\
p=0.03\end{array}$ & $\begin{array}{c}-1.26 \\
p=0.67\end{array}$ & $\begin{array}{c}4.70 \\
p=0.004\end{array}$ \\
\hline $\begin{array}{l}\text { Immediately } \\
\text { after EP }\end{array}$ & $29.63 \pm 1.62$ & & & $\begin{array}{c}2.76 \\
p=0.34\end{array}$ & $\begin{array}{c}8.73 \\
\mathrm{p}=0.001\end{array}$ \\
\hline $\begin{array}{l}\text { One month } \\
\text { after EP }\end{array}$ & $32.40 \pm 1.44$ & & & & $\begin{array}{c}5.96 \\
p=0.002\end{array}$ \\
\hline $\begin{array}{l}\text { Three months } \\
\text { after EP }\end{array}$ & $38.36 \pm 1.01$ & & & & \\
\hline
\end{tabular}


Table 2. Pairwise comparisons of the personal mean differences between the scores for life pattern of the old women with chronic pain before EP, immediately, one month, and three months after

\begin{tabular}{|c|c|c|c|c|c|}
\hline $\begin{array}{l}\text { Changes in } \\
\text { mean scores } \\
\text { for } \\
\text { life patterns }\end{array}$ & Mean \pm SD & Before EP & $\begin{array}{c}\text { Immediately after } \\
\text { EP }\end{array}$ & $\begin{array}{l}1 \text { month after } \\
\text { EP }\end{array}$ & $\begin{array}{c}3 \text { months after } \\
\text { EP }\end{array}$ \\
\hline Before EP & $15.63 \pm 4.97$ & & $\begin{array}{c}2.86 \\
p=0.02\end{array}$ & $\begin{array}{l}-0.40 \\
p=1\end{array}$ & $\begin{array}{c}4.50 \\
p=0.000\end{array}$ \\
\hline $\begin{array}{l}\text { Immediately } \\
\text { after EP }\end{array}$ & $12.76 \pm 5.39$ & & & $\begin{array}{c}-3.26 \\
p=0.005\end{array}$ & $\begin{array}{c}-7.36 \\
p=0.000\end{array}$ \\
\hline $\begin{array}{l}\text { One month } \\
\text { after EP }\end{array}$ & $16.03 \pm 5.06$ & & & & $\begin{array}{c}-4.10 \\
p=0.000\end{array}$ \\
\hline $\begin{array}{l}\text { Three months } \\
\text { after EP }\end{array}$ & $20.13 \pm 3.87$ & & & & \\
\hline
\end{tabular}

trend with a gentle slope first but then rose with a relatively steep slope (Figure 1).

The differences between the mean scores for life pattern before EP and immediately after $(\mathrm{p}=0.03)$ and three months after it $(\mathrm{p}=0.004)$ were significant. Moreover, the mean scores for immediately after EP and one month after EP were significantly different from that for the three months after EP $(p=0.002),(p=0.001)$ (Table 1). The means of the sums of the scores for the personal life pattern received by the old women with chronic pain immediately after EP (12.76 \pm 5.39$)$ decreased compared to that before EP $(15.63 \pm 4.97)$, whereas the scores at one month $(16.03 \pm 5.06)$ and 3 months after EP $(20.13 \pm 3.87)$ increased compared to that before EP. The mean score for the personal life pattern of the old women with chronic pain before EP was significantly different from that of immediately after the EP $(p=0.02)$ and from that of three months after EP $(\mathrm{p}=0.000)$. The score for immediately after the EP had statistically significant differences with that of one month after EP $(p=0.005)$ and with that of 3 months after EP $(p=0.000)$. Moreover, the score for 1 month after EP was significantly different from that of 3 months after EP $(p=0.000)$ (Table 2). The means of the sums of the scores for the social life pattern of the old women with chronic pain immediately after the

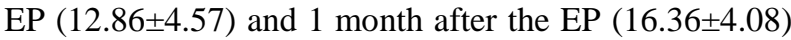
decreased compared to that for before the EP, and only the score for 3 months after the EP $(18.23 \pm 3.47)$ increased compared to the other stages. However, the mean score received for life pattern by the old women with chronic pain before EP was not significantly different from any of those for after EP. Among the stages after EP, only the score for 1 month after the EP was significantly different from that of three months after $\operatorname{EP}(\mathrm{p}=0.005)$ (Table 3).

\section{Discussion}

The findings showed that the mean scores for life pattern with chronic exhibited a declining trend with a gentle slope after the EP for palliative care but, three months after the EP, the scores demonstrated an ascending trend with a relatively steep slope. These findings agree with those of Sadat Bahador et al. (2017). ${ }^{21}$ Despite this average rise in the scores for the stages after the EP can be a sign indicating the success of the EP, the drop in the mean scores for the two stages of immediately and one

Table 3. Pairwise comparisons between the mean scores received for the social life pattern by the old women with chronic pain for before the EP and for immediately and 1 and 3 months after the EP

\begin{tabular}{|l|c|c|c|c|c|}
\hline $\begin{array}{l}\text { Changes in the mean } \\
\text { scores for the social } \\
\text { life patterns }\end{array}$ & Mean \pm SD & Before EP & $\begin{array}{c}\text { Immediately } \\
\text { after the EP }\end{array}$ & 1 month after EP & 3 months after EP \\
\hline Before EP & $18.03 \pm 3.54$ & & $\begin{array}{c}1.16 \\
\mathrm{p}=0.633\end{array}$ & $\begin{array}{c}1.16 \\
\mathrm{p}=0.091\end{array}$ & $\begin{array}{c}-0.20 \\
\mathrm{p}=1\end{array}$ \\
\hline Immediately after EP & $16.86 \pm 4.57$ & & & 0.50 \\
$\mathrm{p}=1$ & $\mathrm{p}=0.47$ \\
\hline 1 month after EP & $16.36 \pm 4.08$ & & & & -1.86 \\
\hline 3 months after EP & $18.23 \pm 3.47$ & & & & \\
\hline
\end{tabular}


month after the EP, and the considerable increase of the scores for the stage of three months after the EP, suggest that changes in previous knowledge and in internalized patterns are accompanied by the challenge of the passage of time. Furthermore, low educational levels and the age of the old women in the present study, and the physiological changes during old age, can also be important and influential factors. ${ }^{28}$

Pairwise comparisons of the mean of each stage with those of the other stages also indicate that the mean score for life pattern with chronic pain in the stage before the EP was significantly different from those of the stages of immediately and three months after the EP. This result conforms to the result that Brumley et al. (2007) obtained in their research. ${ }^{29}$ The scores for the stages of immediately and one month after the EP were only significantly different that of three months after the EP. This result is in agreement with that Sadat Bahador et al. (2017) found in their study. ${ }^{30}$ It seems that changes in the mean score for life pattern with chronic pain immediately after the EP could have been influenced by what was learned in the atmosphere of the educational sessions. The one-month interval might have been insufficient for changing the previous findings and for take caring and using what was learnt as a model in daily life. However, the effect that the EP had after three months can be important due to the influence of the palliative care methods in the life pattern and because of the sufficient time for employing and repeating these methods. ${ }^{21}$

In the present research, teaching palliative care methods also changed each stage compared to the others in the personal life pattern. So that the mean score immediately after the EP was lower compared to that of the stage before the EP. This finding conforms to what Sadat Bahador et al. (2016) found in their research. ${ }^{30}$ However, the mean scores for the stages of 1 and 3 months after the EP increased in line with the findings of the research Jones (2015) carried out. ${ }^{31}$ Moreover, pairwise comparison of the means revealed that the mean score for the stage before the EP was significantly different from those of immediately and three months after the EP, and also there were significant differences between the mean score for the stage of one month after the EP and the stage of three months after the EP. These findings agree with those of the research Evangelista (2012) conducted. ${ }^{23}$ Effects of palliative care education on personal life patterns such as reduced physical and mental capabilities, sedentary lifestyle, inability to perform personal tasks, necessity of taking medications and/or needing help to take treatment and health-related actions with respect to chronic pain was somehow accompanied by transition from short-term (immediately after the EP) to long-term (1 or 3 months after the EP). Moreover, sufficient and suitable inpatient and outpatient follow-up provided the old women with an opportunity to apply what they learned in the EP to their daily life and to adapt to new knowledge. Wettstein et al. (2018) believe that disability related to chronic pain can change personal quality of life and life pattern. ${ }^{32}$ Zanussi et al. (2008) also stated that chronic pain caused changes in personal life pattern and destroyed physical and mental strengths of the individual that were required to confront problems. ${ }^{33}$ They stated that teaching palliative care could preserve and promote physical activity of the individual and help in adapting to stressful events over time. ${ }^{34}$ Adaptation to stressful events and goal-oriented treatment and care methods can influence pain management and improve personal and social life pattern.

Results of analysis regarding social life pattern of the old women with chronic pain indicated that changes happened by teaching palliative care in the stages before and after the EP; i.e., the effect of teaching palliative care on the life pattern of the old people with chronic pain in the stage immediately and one month after the EP declined compared to the stage before the EP. This was in line with Deing et al. (2014). ${ }^{35}$ However, this effect in the stage of 3 months after the EP slightly improved the life pattern compared to that of before the EP. Furthermore, in the pairwise comparisons of the social life patterns, only the stage of 1 month after the EP was significantly different from the stage of 3 months after the EP, and no significant differences were observed in the other stages.

Therefore, we can say that teaching palliative care was not able to cause any short-term change and/or effect in the social life pattern of the old women with chronic pain. This is in line with research Ziehm et al. (2016) conducted. $^{36}$ It appears that the nature of social life pattern in the old women with chronic pain such as receiving consultation and advice from others, having occupational and financial problems, needing care, requiring help from others etc. are not problems that can be modified rapidly only through teaching palliative care and even by spending time. In other words, other factors may help and be influential in this regard and/or act as mediators. Based on the general result of the present research teaching palliative care was able to significantly change life pattern of the old women with chronic pain. Mardani Hamouleh et al. (2015) acknowledge that performing educational programs on palliative care in intervals and carrying out follow up can create the inclination in people to change their personal and social behaviors and is able to gradually influence their living condition. $^{37}$

Limitations of the present study were the possibility for the old women to acquire information from mass media such as educational programs broadcast by radio and television (that was out of our control), and the impossibility of having a period longer than three months for measuring the effects of teaching palliative care on the old women. A more comprehensive research with follow up periods of 6 months and one year woud obtain a better picture of the long-term effect of teaching palliative care. Anyhow, teaching palliative care did influence life pattern of old women with chronic pain, the greater change in our study being observed 3 months or 
more after EP. Therefore, we can conclude that sufficient time plays a very important role in transferring information and in teaching palliative care to old people, though life pattern is a concept that changes with time.

\section{List of acronyms}

EP - educational program

\section{Authors contributions}

$\mathrm{EH}$ is a MSc in Geriatric Nursing, Golestan University of Medical Sciences, Gorgan, Iran; ZS and SK are Assistant Professors, Nursing Research Center, Golestan University of Medical Sciences, Gorgan, Iran.

All authors played a substantial role in study design, data acquisition and/or analysis, as well as in drafting of the manuscript.

\section{Acknowledgments}

The authors would like to express hereby extend our sincere gratitude to the respectable Research and Technology Deputy of Golestan University of Medical Sciences. Gorgan, Iran, Mirdamad Elderly Day Center staff, Gorgan, Iran and the elderly women who collaborated with the study.

\section{Funding}

Extracted from a M.Sc thesis on geriatric nursing, supported by Golestan University of Medical Sciences, Gorgan, Iran.

\section{Conflict of Interest}

The authors declare no conflicts of interest.

\section{Ethical Publication Statement}

The Ethics Committee of the university approved the study (IR.COUMS.REC.1379.071) and registered at the Iranian Clinical Trials Site (IRCT20180910040988N1). We confirm that we have read the Journal's position on issues involved in ethical publication and affirm that this report is consistent with those guidelines.

\section{Corresponding Author}

Shohreh Kolagari, Assistant Professor, Nursing Research Center, Golestan University of Medical Sciences, Gorgan, Iran.

Email: shohrehkolagari@gmail.com

\section{E-mails of co-authors}

Elham Hesari: e.hesari1367@yahoo.com Zahra Sabzi: zsgorgan@yahoo.com

\section{References}

1. Salahshoori A, Harooni J, Salahshoori S, et al. Investigation on association between self-efficacy, perceived barriers and social supports with health promoting behaviors in elderly in Dena city. Health System Research Journal 2015;11:30-42.

2. Nikkhah M, Heravi Karimoui M, Rezhe N, et al. Measuring the Quality of Life of the Elderly: A Review of Measurement Tools. Journal of the
Iranian Institute for Health Sciences Research 2017;16:303-14.

3. Shirazi M, Manoochehri H, ZagheriTafreshi M, et al. The Association of chronic pain acceptance, life style and restriction related chronic pain in elderlies. Scientific Journal of hamedan nursing and midwifery faculty (Nasim-Danesh) 2016;24:14858.

4. Khalili F, Sam S, Sharifirad G, et al. The Relationship between Perceived Social Support and Social Health of the Elderly of Isfahan. Journal of Health Research 2011;7(6) ):1216-25. [Persian].

5. White SA. Increasing longevity: the challenges of aging and caregiving. Journal of vascular nursing 2008;26:96-9.

6. Brennan F, Cousins MJ. Pain relief as a human right. Pain Clinical Updates 2004;12:1-4.

7. Heidari S, Kamali A, Rakei Esfehani S, Amini M. Comparison of Epidural Block and Apotel in Controlling Pain among Patients with Rib Fracture. International Journal of Pharmaceutical Research 2019;11(2). doi: 10.31838/ijpr/2019.11.02.054

8. Cravello L, Di Santo S, Varrassi G, et al. Chronic Pain in the Elderly with Cognitive Decline: A Narrative Review. Pain and therapy 2019;8:53-65.

9. Shirazi M, Manouchehri H, ZaghariTafreshi M, et al. Chronic pain management in the elderly: a qualitative research. Nursing and Midwifery Clinical Journal 2015;4:13-28.

10. Shi Y, Hooten WM, Roberts RO, Warner DO. Modifiable risk factors for incidence of pain in older adults. Pain 2010;151:366-71.

11. Elder NC, Simmons T, Regan S, Gerrety E. Care for patients with chronic nonmalignant pain with and without chronic opioid prescriptions: a report from the Cincinnati area research group (CARinG) network. The Journal of the American Board of Family Medicine 2012;25:652-60.

12. Simon LS. Relieving pain in America: A blueprint for transforming prevention, care, education, and research. Journal of pain and palliative care pharmacotherapy 2012;26:197-8.

13. Vadalouca A, Raptis E, Moka E, et al. Pharmacological treatment of neuropathic cancer pain: a comprehensive review of the current literature. Pain Practice 2012;12:219-51.

14. Schofield P. The management of pain in older people. Schofield P editor. Chichester: John Wiley \& Sons; 2007.

15. Veal FC, Peterson GM. Pain in the frail or elderly patient: does tapentadol have a role? Drugs and aging 2015;32:419-26.

16. Gómez-Batiste X, Porta-Sales J, Pascual A, et al. Catalonia WHO palliative care demonstration project at 15 years (2005). Journal of pain and symptom management 2007;33:584-90.

17. Negarandeh R, Mardani Hamooleh M, Rezaee N. Concept Analysis of Palliative Care in Nursing: 
Introducing a Hybrid Model. Journal of Mazandaran University of Medical Sciences 2015;25:40-51

18. Coelho A, Parola V, Cardoso D, et al Use of nonpharmacological interventions for comforting patients in palliative care: a scoping review. JBI database of systematic reviews and implementation reports 2017;15:1867-904.

19. Mizuno A, Shibata T, Oishi S. The Essence of Palliative Care Is Best Viewed as the "Problematization". Journal of palliative medicine 2019;22:6.

20. Orzechowski R, Galvao AL, Nunes TDS, Campos LS. Palliative care need in patients with advanced heart failure hospitalized in a tertiary hospital. Revista da Escola de Enfermagem da U S P. 2019;53:413.

21. Sadat Bahador RS, Nouhi E, Jahani Y. The study of palliative care and its relationship with quality of life in patients with chronic heart failure. in 2014 2015. Journal of Clinical Nursing and Midwifery 2017;5:35-46.

22. Campbell L, Amin N. A poststructural glimpse at the World Health Organization's palliative care discourse in rural South Africa. Rural and Remote Health 2012;12: :2059.

23. Evangelista L, Lombardo D, Malik S, et al. Examining the effects of an outpatient palliative care consultation on symptom burden, depression, and quality of life in patients with symptomatic heart failure. Journal of cardiac failure 2012;18:894-9.

24. Mojen LK, Rassouli M, Eshghi P, et al. Palliative care for children with cancer in the Middle East: A comparative study. Indian journal of palliative care 2017;23:379.

25. Morrison RS. Research priorities in geriatric palliative care: An introduction to a new series. Journal of palliative medicine 2013;16:726-9.

26. Gutgsell KJ, Schluchter M, Margevicius S, et al. Music therapy reduces pain in palliative care patients: a randomized controlled trial. Journal of Pain and Symptom Management 2013;45:822-31.

27. Shirazi M M, ZagheriTafreshi M, Zayeri F, AlipourV. Design and validation of life pattern with chronic pain in elderly. Quarterly Journal of Nursing of vulnerable groups. 2015;2:15-36.

28. Shirazi M, Manouchehri H, ZagheriTafreshi M, et al. An explanation of the chronic pain management process in the elderly: a grounded theory study.
Quarterly Journal of Internal and Surgical Nursing 2015;4:1-11.

29. Brumley R, Enguidanos S, Jamison P, et al. Increased satisfaction with care and lower costs: results of a randomized trial of in-home palliative care. Journal of the American Geriatrics Society 2007;55:993-1000.

30. Sadat Bahador RN, Ghanbarzehi N, Arefi F, Afrazandeh SS. The impact of palliative care program on quality of life in patients with chronic heart failure. International Journal of pharmaceutical Research and Allied Sciences 2016;5:174-9.

31. Tinetti M, Reuben D, Allman R, Cassel Ch. Goaloriented chronic care: defining concepts and developing tools. The George Washington University. 2015.

32. Wettstein M, Eich W, Bieber C, Tesarz J. Pain Intensity, Disability, and Quality of Life in Patients with Chronic Low Back Pain: Does Age Matter? Pain Medicine 2018;8:30-40.

33. Zanoochi M, Maero B, Nicola E, et al. Chronic pain in a sample of nursing home residents: prevalence, characteristics, influence on quality of life (QoL). Archives of gerontology and geriatrics 2008;47:121-8.

34. HedayatizadehI A, Janbabaei G, Faraji M, et al. Relationship Between Spirituality and Death Anxiety in Cancer Patients Under Chemotherapy. Journal of Mazandaran University of Medical Sciences 2018;27:98-108.

35. Denig P, Schuling J, Haaijer-Ruskamp F, Voorham J. Effects of a patient oriented decision aid for prioritising treatment goals in diabetes: pragmatic randomised controlled trial. Bmj 2014;349:5651.

36. Ziehm J, Farin E, Schäfer J, et al. Palliative care for patients with heart failure: facilitators and barriersa cross sectional survey of German health care professionals. BMC health services research 2016;16:361.

37. Mardani Hamoole M, Borimnejad L, Seyedfatemi $\mathrm{N}$, Tahmasebi M. Interpretation of palliative care concept, its barriers and facilitators using metasynthesis Modern care journal. Modern care journal 2015;11(4):316-29.

Submission: August 06, 2019

Revision received: September 05, 2019

Acceptance: September 07, 2019 